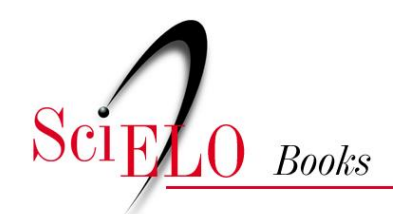

\title{
Seduepb
}

\section{A figura do Diabo nos Sueños de Quevedo}

\author{
Andréa Cesco
}

\section{SciELO Books / SciELO Livros / SciELO Libros}

CESCO, A. A figura do Diabo nos Sueños de Quevedo. In MAGALHÃES, ACM., et al., orgs. $O$ demoníaco na literatura [online]. Campina Grande: EDUEPB, 2012. pp. 91-102. ISBN 978-85-7879188-9. Available from SciELO Books <http://books.scielo.org>.

\section{(2)(1)(2)}

All the contents of this work, except where otherwise noted, is licensed under a Creative Commons Attribution-Non Commercial-ShareAlike 3.0 Unported.

Todo o conteúdo deste trabalho, exceto quando houver ressalva, é publicado sob a licença Creative Commons Atribuição Uso Não Comercial - Partilha nos Mesmos Termos 3.0 Não adaptada.

Todo el contenido de esta obra, excepto donde se indique lo contrario, está bajo licencia de la licencia Creative Commons Reconocimento-NoComercial-CompartirIgual 3.0 Unported. 


\title{
A figura do Diabo nos Sueños de Quevedo
}

\author{
Andréa $\operatorname{Cesco}^{1}$ (UFSC)
}

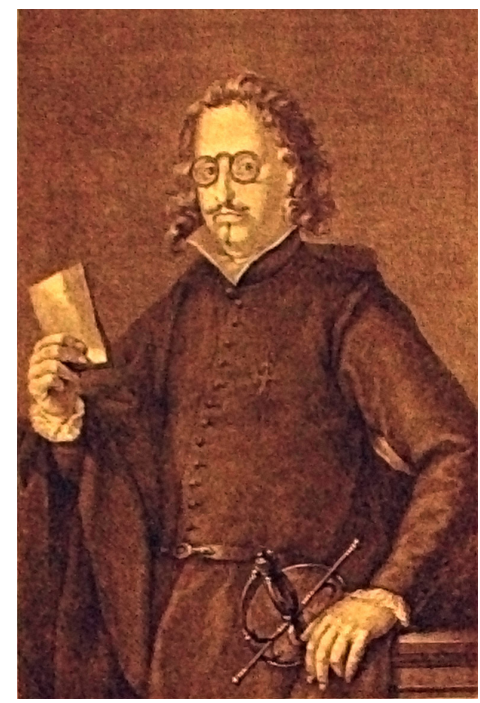

Este artigo tem por objetivo principal analisar a figura do diabo na obra satírica Sueños, escrita no século XVII pelo espanhol Francisco de Quevedo y Villegas, com base na reconhecida edição de James Crosby (Sueños y discursos. Madrid: Castalia, 1993). Também buscaremos analisar os traços típicos do estilo satírico, como a presença de palavras e expressões idiomáticas da língua coloquial e vulgar e a produção de burlas e humor. Este estilo se caracteriza pela reiteração direta ou por repetições com variantes de lexemas predicados para os mesmos sujeitos. O conceito

1 Professora Adjunta do Departamento de Língua e Literatura Estrangeiras e da PósGraduação em Estudos da Tradução da Universidade Federal de Santa Catarina. Email: andrea.cesco@gmail.com 
no discurso satírico é construído sobre o jogo de palavras ou metáforas (ou uma combinação destas com outras figuras) com o propósito de produzir riso no leitor e, ao mesmo tempo - pelo menos em alguns casos -, convidá-lo a refletir sobre a terrível realidade que se apresenta.

A obra Sueños é composta por cinco narrativas, porém nos focaremos no "Alguacil endemoniado" e no "Infierno", textos que satirizam costumes e personagens de todas as classes sociais, através da figura do diabo, e que são extremamente criativos no uso da linguagem coloquial, pois proporcionam o retrato da realidade social da Espanha no século XVII.

\section{"Alguacil endemoniado"}

No primeiro texto, "Alguacil endemoniado", que é uma forte sátira à igreja, temos um diálogo entre o narrador, o bacharel e o diabo, que ocupa a maior parte do discurso e que desempenha o papel principal. A história inicia quando o narrador entra na igreja de São Pedro e encontra o bacharel Calabrês, que é descrito de forma bastante detalhada, entregue a sua ocupação favorita, exorcizando um demônio de um meirinho (alguacil). Esse demônio concede uma breve trégua a sua vítima e conta aos dois, narrador e Calabrês, como vão os clientes no inferno. Ou seja, o próprio demônio que possui o meirinho é quem descreve os diferentes lugares do inferno.

O narrador faz ao diabo uma série de perguntas do tipo "Há reis no inferno?", "Que tipos de penas dão aos poetas?", "E as mulheres, quais são mais condenadas, as feias ou as bonitas?” (tradução nossa). ${ }^{2} \mathrm{E}$ o diabo the responde com uma série de descrições burlescas, dando a entender o caráter geral do inferno e afirmando a superioridade moral e intelectual dos diabos sobre a maioria dos homens.

O diálogo, muitas vezes, se converte num sermão moralizante sobre os benefícios da pobreza, a arte de governar etc. Nesse texto aparecem avaros, médicos, poetas, damas honestas ou não, comerciantes, pasteleiros, administradores da justiça, cornos, e aparecem também os apaixonados. É importante destacar que nesse texto os condenados estão agrupados segundo analogias engenhosas: o cego está entre os apaixonados, um assassino está entre os médicos, os mentecaptos junto aos alquimistas, e os negociantes, condenados por vender, estão com Judas.

2 “¿Hay reyes en el infierno?”, “¿Qué géneros les dan de penas a los poetas?”, "Y las mujeres, ¿cuáles se condenan más, feas o hermosas?” 
Segundo Crosby (QUEVEDO Y VILLEGAS, 1993, p. 28), a sátira de Calabrês como exorcista que tenta calar um diabo coincide com a crítica que Quevedo faz no prólogo dos que se calam por temor, dos que procuram deixar outros mudos, e daquelas más línguas que alimentavam um ambiente de repressão religiosa. Aqui, segundo o crítico, está o tema da expressão e da repressão, em que o narrador apóia a expressão, coincidindo com as palavras de Quevedo no prólogo ao leitor, em que elogiava a ousadia dos que se atrevem a publicar suas ideias. Esse texto é uma sátira à igreja, que não fica no mero plano abstrato.

No entanto, é importante fazer um aparte para explicar quem é o alguacil e o que ele fazia nessa época, já que chegam a inspirar os mais sangrentos sarcasmos do satírico barroco. O meirinho e os seus subordinados - os beleguins -, são agentes da lei que colocam em marcha o procedimento criminal e que no civil executam os mandamentos do juiz. Nesse texto, Quevedo parte da base das notáveis afinidades entre meirinhos e demônios, e enumera até seis ordens conhecidas de meirinhos, que vêm a coincidir com as potências demoníacas: Os ígneos, os aéreos, os terrenos, os aquáticos, os subterrâneos e os lucífugos (QUEVEDO Y VILLEGAS, 1993, p. 154).

Os ígneos são de natureza violenta e criminal, que perseguem o gênero humano a sangue e fogo; que perseguem os réus pelas ruas para agarrá-los e culpá-los, levantando falso testemunho. Os aéreos são os que sopram, pois são os delatores profissionais (os beleguins também são acusados de denunciar). Os terrenos são os civis, que à força de comissões e execuções destroem a terra; estes roubam o povo mediante a falsificação de embargos judiciais. Os aquáticos são os encarregados do cumprimento das ordenanças municipais em matéria de sanidade e polícia, prendendo o sujeito se este esvazia ou não as imundices pelas portas e janelas, sem dizer "Vai água!", ${ }^{3}$ e assim costumam ser chamados porque quase todos são bêbados e sequiosos por vinho. Os subterrâneos são os investigadores de vidas, fiscais de honras e levantadores de falsos testemunhos, que debaixo da terra arrancam o que acusar, e andam

3 No século XVI ao XVIII costuma-se esvaziar as águas imundas de cada casa diretamente na rua, antecipadas pelo grito de 'Vai água!', avisando assim os que passeiam pela rua. As autoridades de Madri tentaram repetidamente limitar as horas de lançar as águas para altas horas da noite (quando menos pessoas passeavam) e proibir que fossem jogadas de janelas altas (nota do editor - Crosby). 
sempre desenterrando os muertos e enterrando os vivos (QUEVEDO Y VILLEGAS, 1993, p. 156). Os últimos são os lucífugos, os que fazem as rondas noturnas para manter a ordem e vigiar as cidades, e estes fogem da luz porque ela pode denunciar as suas falcatruas; no entanto, a luz, que representa a iluminação interior e o juízo, e tudo que é bom e santo, é que deveria fugir deles.

Retomando o texto "Alguacil endemoniado", Calabrês na passagem abaixo se enfurece com o diabo que não quer se calar, e jogando-lhe água benta nas costas professa palavras para esconjurá-lo; este, porém, começa a gritar tentando escapulir. A partir daí o próprio diabo explica ao clérigo que o meirinho tenta escapar por causa da água e não da benzedura, e o faz detalhando a etimologia da palavra alguacil, pois esta se assemelha fonologicamente a água. E para Quevedo os alguaciles, além de mentirosos e usurpadores, eram bêbados que, evidentemente, não suportavam a água.

Clérigo, cata que no hace estos sentimientos el alguacil por la parte de bendita, sino por ser agua: ¿Hay cosa que tanto aborrezcan los alguaciles? Pues aun por no verla en su nombre llamándose propiamente 'aguaciles', han encajado una ele en medio, llamándose 'alguaciles'. Y por qué acabéis de conocer quién son y cuán poco tienen de cristianos, advertid que de pocos nombres que del tiempo de moros quedaron en España, llamándose ellos 'merinos', le han dejado por llamarse 'alguaciles', que es palabra morisca, 'guacil'; y hacen bien, que conviene el nombre con la vida y ella con sus hechos (QUEVEDO Y VILLEGAS, 1993, p. 163).

Então, para os alguaciles a água lhes aborrece tanto que para não escutarem essa palavra, ao ser pronunciado alguacil, colocaram um "l" no meio, já que sem ela soaria "agua-cil". Crosby, em nota de rodapé, explica que essa palavra deriva de wasir (árabe: ministro, visir), precedido pelo artigo árabe, "al"; e acrescenta que a partir do Poema del Cid surgiu em espanhol o vulgarismo aguazil, empregado ainda por alguns copistas no século XVII. Quevedo, para fazer uma piada com a palavra água, inverteu o processo de vulgarização, atribuindo a intercalação da letra "l" à vontade dos alguaciles. 
Nessa outra passagem, o alguacil endemoniado (o meirinho que está com o diabo no corpo) vira diabo alguacilado; ou seja, contrariamente à expectativa é o diabo que vai estar com o meirinho no corpo. Ao longo do texto o diabo manifesta nitidamente uma atitude de superioridade intelectual em relação aos homens. E Quevedo desumaniza os meirinhos, colocando-os numa situação inferior; ademais, se queixa de que o contato com eles resulta degradante para os diabos. A correspondência entre as funções diabólicas e meirinhais descansa no fato de que ambas se fundamentam em querer o mal dos humanos.

Y hase de advertir que los diablos en los alguaciles estamos por fuerza y de mala gana, por lo cual, si queréis acertar, me debéis llamar a mí diablo alguacilado, y no a éste alguacil endemoniado (QUEVEDO Y VILLEGAS, 1993, p. 161-2).

O estilo de Quevedo é rico também em neologismos, muitos deles produzidos pelo cruzamento de palavras. E esse tipo de invenção verbal é no satírico um elemento lúdico que contribui para o efeito de comicidade. Emilio Alarcos García, no artigo "Quevedo y la parodia idiomática", ${ }^{4}$ diz que as paródias são "flor e fruto do espírito corrosivo e zombador de Quevedo, da sua mentalidade de escolástico habituado ao discurso afiado e à argumentação refinada, e de sua fantasia deformadora e desrealizadora de coisas e atitudes". ${ }^{5}$ (tradução nossa)

No entanto, pelos parágrafos dos Sueños, além dos meirinhos infames, desfilam outros agentes da justiça, como juízes e escrivães corrompidos, relatores desonestos, advogados desleais, toda uma tipologia que nos transporta a uma realidade cujas dimensões, segundo Gacto Fernández (in GARCÍA DE LA CONCHA, 1996, p. 133-4), dificilmente seríamos capazes de captar mediante o exame das fontes jurídicas, normas, documentos e sentenças.

Quevedo critica nos juízes a tentação mais perigosa do seu oficio, a cobiça. Gacto Fernández ressalta que num sistema normativo de

4 Centro Virtual Cervantes - Las sátiras de Quevedo y su recepción: antología crítica. Recopilación de Lía Schwartz. http://cvc.cervantes.es/obref/quevedo_critica/satiras/alarcos.htm

5 “flor y fruto del espíritu mordicante y burlón de Quevedo, de su mentalidad de escolástico avezado al discurso afilado y a la argumentación sutilizante, y de su fantasía deformadora y desrealizadora de cosas y actitudes". 
contornos difusos havia muitas brechas para o jogo do arbítrio judicial, (in GARCÍA DE LA CONCHA, 1996, p. 138). Assim era possível ao julgador manter diversas e até contrárias interpretações de um mesmo texto, e se inclinar pela solução mais benéfica aos interesses do corrupto, sem escândalo, ou pelo menos, sem evidência de suborno.

Neste fragmento, os juízes estão associados à comida; estes são para o inferno e para os diabos o prato mais saboroso: faisão, ave galinácea notável pela excelência da carne. E também a melhor semente, pois é a que mais frutos dá aos diabos. E fruto aqui tem não só o sentido de produto da terra para sustento e beneficio do homem (dos diabos), como também no sentido de dar lucro, vantagem, resultado. E o diabo conclui que se o ano é fértil de trapaças, não há silo suficiente no inferno para recolher o fruto de um mau ministro.

Los jueces son nuestros faisanes, nuestros platos regalados, y la simiente que más provecho y fruto nos da a los diablos; porque de cada juez que sembramos cogemos seis procuradores, dos relatores, cuatro escribanos, cinco letrados y cinco mil negociantes, y esto cada día. De cada escribano cogemos veinte oficiales; de cada oficial, treinta alguaciles; de cada alguacil, diez corchetes; y si el año es fértil de trampas, no hay troj en el infierno donde recoger el fruto de un mal ministro (QUEVEDO Y VILLEGAS, 1993, p. 176-7).

Nesse trecho, quando o diabo fala sobre a acomodação das pessoas no inferno, feita de forma ordenada, levando em conta as afinidades que as combinam, Quevedo utiliza ironicamente os homógrafos. ${ }^{6}$

Y en el infierno están todos aposentados con tal orden que un artillero que bajó allá el otro día, queriendo él que lo pusieran entre la gente de guerra, como al decir el oficio que había tenido, dijese que hacer tiros, fue remitido al cuartel de los escribanos, pues son los que hacen tiros en el mundo. Un sastre,

6 Palavra que tem a mesma grafia de outra, mas significado diferente. 
porque dijo que había vivido de cortar de vestir, fue aposentado con los maldicientes; [...] (QUEVEDO Y VILLEGAS, 1993, p. 167).

$\mathrm{Na}$ primeira parte, que se refere ao soldado de artilharia, o diabo diz que ele queria que o pusessem entre gente de guerra, porque seu oficio havia sido dar "tiros", disparar projétil; porém foi enviado para onde estavam as tropas de escrivães, porque "tiro" significa também, segundo o Diccionario de Autoridades, de 1739, furto, ou grave dano físico ou moral; ou ainda "decepção ou zombaria, enganar alguém maliciosamente". Ou seja, os escrivães são acusados de alterar os depoimentos das testemunhas, agem de má-fé, porque o que importa e prevalece não é a verdade e sim a vontade de quem os suborna.

Na sequência, o alfaiate também será encaminhado para o lugar certo no inferno, com aqueles que armam intrigas ou confusões; e isso porque ele viveu de "cortar de vestir", ou seja, maldizer, difamar. O Diccionario de Autoridades, de 1729, nos mostra dois significados para essa expressão: "fazer vestidos, cortá-los e cosê-los: o que é próprio do ofício dos costureiros" ou "metaforicamente se toma por murmurar e falar mal de alguém”.

\section{"Infierno"}

Quanto ao segundo texto, "Inferno", que é o mais longo e mais complexo, o narrador desce pessoalmente para conhecer as mansões infernais. Tema e título remetem, como atesta Nolting-Hauff, de modo especialmente claro, a Dante. " Talvez a influência de Dante em Quevedo também possa ser explicada por este ter evitado a ficção do sonho e ter escolhido em seu lugar uma introdução alegórica" (1974, p. 22-3) (tradução nossa). ${ }^{8}$ Entretanto, há um ponto em que ele se afasta da tradição dantesca: a figura do poeta no sonho não tem acompanhante ou guia.

7 Um estudo de Rodrigo Cacho Casal oferece novas evidências e análises na interação entre os escritos de Dante e Quevedo. Dante y Quevedo: la Divina Commedia en los Sueños. Manchester: Manchester Spanish \& Portuguese Studies: Cañada Blanch, 2003.

8 Quizá también se pueda explicar por la influencia de Dante el que Quevedo evitara la ficción del sueño y eligiera en su lugar una introducción alegórica" (1974, p. 22-3). 
O panorama agora é mais extenso, mas os motivos quase não variam. $\mathrm{Na}$ introdução desse sonho é descrita uma paisagem agradável e dela partem dois caminhos; logo saberemos que um deles é o caminho da virtude e o outro conduz ao inferno. Ingressando o narrador pelo caminho do bem, mas demonstrando não estar satisfeito com a sua escolha, por ser este um caminho muito penoso, decide mudar, mas não percebe que a sua escolha o leva diretamente ao inferno. E quando se dá conta já é tarde para voltar.

Gómez-Quintero (1978, p. 78-9) chama a atenção do leitor, porque até este momento o narrador está situado no mesmo plano que os demais: escolhe o caminho mais fácil e por ele se lança como um condenado ao inferno. Porém, a partir de agora visitará o inferno como um espectador. E no final do texto, de condenado ele passa a mensageiro de Lúcifer, mudando completamente a sua posição. Além disso, ele muda frequentemente de atitude e por várias vezes titubeia: não sabe qual caminho seguir, escolhe um caminho, depois desiste e muda; e quando chega ao inferno muda totalmente de atitude: julga, repreende e zomba dos condenados porque não está entre eles; fala de um ponto de vista de quem está seguro de não pertencer ao grupo repreendido. E é esta atitude, de espectador-crítico, que mantém em todos os sonhos.

O texto se desvia do caminho da virtude e segue a história entre juízes, hipócritas, mulheres, eclesiásticos, soldados, boticários. Os diabos repartem castigos numa série heterogênea que inclui açougueiros, fidalgos, tintureiros, cornos, canhotos, taberneiros, poetas, alquimistas e astrólogos. Aparecem Lutero, Maomé e Judas. No entanto, aparecem alguns retratos novos como os "mortos de repente", que por morrerem de forma repentina não tiveram tempo de se arrepender dos pecados, e os "Oh, quem me dera tivesse", que confiaram na misericórdia de Deus, e agora isso se converte em motivo de condenação para eles. No mais, Quevedo vai continuar agitando os mesmos fantoches das formas mais variadas e originais.

Nessa passagem do "Infierno", vamos encontrar vários jogos alusivos. Nela o diabo acusa os comerciantes de ladrões porque estes, em vida, sempre procuraram tirar vantagem de qualquer negócio realizado, usando as "varas" (antiga unidade de medida de comprimento / instrumento de madeira usado para medir) fraudulentas e impostoras. 
“- Pensaron los ladronazos que no había más, y quisieron con la vara de medir hacer lo que Moisés con la vara de Dios, y sacar agua de las piedras”. (QUEVEDO Y VILLEGAS, 1993, p. 214).

Quevedo faz uma alusão a uma passagem da Bíblia em que Moisés, estando em Horebe, fere a rocha com sua vara (bastão) e dali retira água para o povo beber (Êxodo, capítulo 17, versículos 2 a 10). Os comerciantes, segundo o diabo, querem fazer o mesmo que Moisés, e tirar água de pedras, ou seja, através das varas fraudulentas eles usam todos os meios e se empenham para conseguir o que querem: lucrar com base na fraude.

Neste outro trecho, a escuridão das vendas propicia o dolo dos comerciantes e as medidas falsas, então, como consequência, eles asseguram para si a escuridão absoluta. $\mathrm{O}$ diabo irritadiço os questiona e sentencia:

Mas ¿quién duda que la oscuridad de sus tiendas les prometía estas tinieblas? Gente es ésta (dijo al cabo muy enojado) que quiso ser como Dios, pues pretendieron ser sin medida; mas Él que todo lo ve les trajo de sus rasos a estos nublados, que los atormentan con rayos (QUEVEDO Y VILLEGAS, 1993, p. 214).

Aqui o jogo se faz baseado em homógrafos e antônimos. Quevedo explora ao máximo a palavra "raso", que segundo o Diccionario de Autoridades, de 1737 , se refere tanto a um tipo de tecido vendido pelos comerciantes quanto ao céu limpo, sem nuvens. Então, nessa passagem, rasos se opõe a nublados (coberto de nuvens), que logo em seguida se atrela à palavra rayos, pois nublado é também uma nuvem que ameaça tormenta (temporal/desordem, agitação). Na comparação dos comerciantes com Deus também há um trocadilho: pois quiseram ser sin medida (grandiosos, infinitos) como Ele, ou seja, através de falsas medidas com as varas de medir.

Nesta outra passagem, em que o fidalgo injuriado toma a palavra e se vangloria da sua linhagem, como se esta lhe protegesse de qualquer condenação, encontra-se o emprego cômico de homógrafos e antônimos referentes a partes do corpo: 
- Pues si mi padre se llamó tal de cual, y soy nieto de tales y cuales, y ha habido en mi linaje trece capitanes valerosísimos, y de parte de mi madre doña Rodriga desciendo de cinco catedráticos, los más doctos del mundo, ¿cómo me puedo haber condenado? y tengo mi ejecutoria y soy libre de todo y no debo pagar pecho. -Pues pagad espalda, -dijo un diablo, y diole cuatro palos en ellas, que le derribó de la cuesta. Y luego le dijo: [...] (QUEVEDO Y VILLEGAS, 1993, p. 216).

O jogo irônico, demolindo o argumento do interlocutor, se faz através dos vocábulos pecho (peito) e espalda (costas). Porém pecho é usado também como "o tributo pago ao rei pelos que não são fidalgos" (Diccionario de Autoridades, de 1737).

No "Infierno", as graças dos cômicos, patifes, trovadores e piadistas são tão frias, e deixam o ambiente tão frio, que os diabos que os vigiam explicam por que: "estão aqui retirados porque se andassem soltos pelo inferno, sua frieza é tanta que atenuaria o calor do fogo" (QUEVEDO Y VILLEGAS, 1993, p. 209) (tradução nossa).

José Montesinos, Dámaso Alonso e Octavio Paz afirmam que Quevedo não teve rival no seu século e nem o tem agora. Para eles, sem dúvida, Quevedo os atrai tanto, por nele existir algo demoníaco: o orgulho (ou o rancor) da inteligência.

Hay que leerlo para saber qué son, realmente, las noches y los días del solitario, el acicate del apetito insaciado, el peso de la sombra de la muerte en la conciencia, las vigilias del rencor, las caídas en la melancolía, el encontrado ir y venir de la cólera al ludibrio y, en fin, toda esa gama de sentimientos y sensaciones que va de la desesperación a la resignación orgullosa. Hecho de contrastes y oposiciones geométricas, violento y simétrico, sentencioso y sarcástico, Quevedo se burla de sí mismo y de los otros [...] (in RICO, 1983, p. 157).

Para Carlos Alberto Loprete (1981, p. 169-170) as cenas são fantásticas e irreais, mas é nesta fantasia que reside a burla; grotescas e caprichosas

9 "están aquí retirados porque si anduvieran por el infierno sueltos, su frialdad es tanta que templara el calor del fuego". 
tornam-se por alguns momentos exorbitantes e sarcásticas. Chegam às vezes ao cinismo e à impiedade, apesar do fundo religioso. Não há nelas nenhum lugar para o amor ou o perdão.

Com a ideia da morte sempre presente, o espetáculo da vida humana atravessa os infernos, com um enorme sarcasmo e uma fúria imaginativa pouco frequentes na literatura. Quevedo traça nos Sueños um quadro satírico da sociedade que não tem estado nem ofício, defeito físico ou moral, ideia ou sentimento, que não estejam representados de maneira grotesca, vivaz e exagerada. 


\section{Bibliografia}

CARPEAUX, Otto Maria. História da Literatura Ocidental. V. II. Rio de Janeiro: O Cruzeiro, 1960.

GARCÍA DE LA CONCHA, Víctor (ed.) e Academia Literaria Renacentista. Homenaje a Quevedo: actas de la II Academia Literaria Renacentista: Universidad de Salamanca, 10, 11 y 12 de diciembre, 1980. $1^{a}$ ed. Reimpressa. Salamanca: Universidad de Salamanca, 1996.

GÓMEZ-QUINTERO, Ela Rosa. Quevedo, hombre y escritor en conflicto con su época. Miami (Flórida): Universal, 1978.

LOPRETE, Carlos Alberto. Literatura española, hispanoamericana y argentina. Buenos Aires: Plus Ultra, 1981.

NOLTING-HAUFF, Ilse. Visión, sátira y agudeza en los "Sueños" de Quevedo. Tradução de Ana Pérez de Linares. Madrid: Gredos, 1974.

QUEVEDO Y VILLEGAS, Francisco de. (edição anotada de James O. Crosby). Sueños y Discursos. Madrid: Castalia, 1993.

RICO, Francisco. Historia y crítica de la literatura española. Siglos de oro: Barroco, V. III, al cuidado de Bruce W. Wardropper [et. al.]. Barcelona: Crítica, 1983.

SCHWARTZ LERNER, Lia. Metáfora y sátira en la obra de Quevedo. Madrid: Taurus, 1983.

\section{Imagens}

Quevedo: Disponível em ttp://2.bp.blogspot.com/_6SsDbu46AJw/ TEOrelXWQwI/AAAAAAAABbE/R5Sv379evkg/s1600/don_francisco_de_ quevedo-villegas.jpg 